\title{
REVISTAS MUSICAIS ESTRANGEIRAS E COMPOSITORES MODERNOS NA BIBLIOTECA DE MÁRIO DE ANDRADE
}

\author{
Flávia Camargo Toni \\ flictis@usp.br
}

\section{INTRODUÇÃO}

Durante o século XIX, o piano e a voz se estabeleceram na Europa e nas Américas como instrumentos populares para a formação dos moços e moças da burguesia: podiam profissionalizar alguns, que se tornavam professores particulares e auxiliavam na complementação da renda familiar, e serviam de entretenimento para outros, nos saraus familiares, por exemplo. A manutenção destas práticas teve, entre outras consequências, o estabelecimento de uma imprensa musical que animou editores e comerciantes na edição regular de partituras. No Brasil, eram polcas, quadrilhas, valsas, modinhas, árias, romances, escritos por L. França, Ernest de Merolla, José Pinto Tavares, Thomaz Teixeira Assunção e uma infinidade de obras anônimas que chegavam aos consumidores. $\mathrm{O}$ romance $O$ gênio de Camões, para canto e piano, partitura da coleção de Mário de Andrade, é típico. Apesar de o autor da música ser identificado como "S P" e o autor da poesia como "J R", no frontispício, a "Publicação Musical de T. B. Diniz", do Rio de Janeiro, não economizou palavras para explicar a circulação d' A Lyra do Trovador: "Publica-se três escolhidas peças de musica por mez, sendo duas para piano só e uma para piano e canto", com assinatura anual e preços diferenciados entre "Corte" e "Províncias". 
As "publicações periódicas de música" ou "edições periódicas de partituras musicais", assim chamadas por Paulo Castagna (2008, p. 3) - e que no Brasil foram representadas por títulos como O Brasil Musical (Rio de Janeiro, 1848-1875) ou Ramalhete das Damas (18421850) -, atendiam a um universo paralelo ao da formação escolar. Para aqueles que pretendiam se aprofundar no estudo teórico da música, este repertório, pode-se dizer que doméstico, que reproduzia os sucessos dos palcos de óperas e operetas, era pouco variado porque não estava vinculado ao exercício da técnica instrumental ou à história e à estética da música. Com a República e a institucionalização dos estudos, para os que procuravam os cursos do Instituto Nacional, do Rio de Janeiro, ou, após 1905, os do Conservatório Dramático e Musical, de São Paulo, foi necessário multiplicar a oferta. Este gênero de publicação tornou-se insuficiente para dar conta da variedade da música sinfônica, de câmara e dos lançamentos ocorridos em outras "praças" de comércio e práticas musicais. Ou as lojas de instrumentos e partituras importavam das editoras ou aqueles que viajavam, a lazer ou estudo, traziam na bagagem.

Porém, era o comércio nutrido pela venda e manutenção de pianos e partituras que alimentava a edição de revistas, publicações que podiam ser mistas, com músicas e artigos, ou apenas com trabalhos teóricos. Sustentar este segundo tipo de publicação - que chamo aqui genericamente de revista, para diferenciar daquela do século XIX acima referida - não era barato, e para tanto lançava-se mão do patrocínio resultante da venda de espaços para o anúncio das sociedades de concertos, escolas de música, casas de ópera e teatros que aproveitavam para divulgar suas atividades. Este periódico de música, que no geral tinha vida efêmera, transitava facilmente através dos continentes até a década de 1940 e, dependendo do país, foi bastante bem conhecido também no contexto do Modernismo.

Para a história da música, há uma série de situações de interesse para análise, desde as propagandas daquelas revistas, como os "Indicadores profissionais" e a oferta de serviços dos professores particulares, até a circulação dos repertórios, como as chamadas para os concertos organizados por empresários e casas de música ou as críticas com espaços garantidos nas colunas especiais. Novamente, muitos estudiosos já se reportaram ao fato de que este tipo de publicação estabelecia elos entre os autores reunidos em um mesmo título, enfeixados com a mesma "capa”, escritores que se comunicavam através das redações, pelo correio ou pessoalmente. E quando algumas destas revistas tinham por editor um intelectual que visava a produção de conteúdo de interesse, nasciam 
verdadeiras redes de comunicação trocando artigos e ilustrações em esfera local, regional ou intercontinental.

Eis um campo pouco explorado na musicologia brasileira, sobretudo se considerarmos compositores e intelectuais como Luciano Gallet, Lorenzo Fernandez e Antônio de Sá Pereira, autores cujos ensaios, artigos e críticas não foram sequer reunidos em livros. Honrosas exceções são, por exemplo, Luiz Heitor Corrêa de Azevedo e Mário de Andrade, contemporâneos, que cuidaram das edições de alguns de seus artigos esparsos, homens que, como os anteriores, trabalharam como editores de revistas, a Revista Brasileira de Música e Ariel, respectivamente'.

No início do século XX, em São Paulo, a atualização do conhecimento para se acompanhar as discussões no campo da música ocorria nos salões de arte ou nas rodas de amigos, onde os recém-chegados das viagens ao exterior mostravam as novidades, mas se dava também através das revistas. Dependendo dos espaços culturais de cada cidade, este meio impresso podia ser mais significativo do que se tem avaliado para a música, noção que certas vezes parece ambígua uma vez que ela se "materializa" através do som. Não que a cidade fosse pobre ou estivesse alheia aos acontecimentos da moda. A cidade e seus intelectuais estavam entrosados com a rotina da arte europeia, o número de artistas mulheres era significativo a se considerar os nomes de Antonieta Rudge, Magda Tagliaferro, Guiomar Novaes, Dinorá de Carvalho e Liddy Chiaffarelli. No entanto, no caso do que se tocava nas salas das escolas e teatros, tanto no Rio de Janeiro quanto em São Paulo, o predomínio era de gosto extremamente conservador, beirando o retrógrado, se considerarmos o Conservatório Dramático e Musical, por exemplo. Logo, os periódicos de música para aqueles que desejavam acompanhar as novas tendências estéticas eram imprescindíveis porque ampliavam artificialmente os espaços sonoros. Tais revistas traziam partituras ou trechos de obras orquestrais, apresentavam artigos de aprofundamento sobre certas questões e, não menos importante, mostravam o que as salas de ópera e música instrumental ofereciam como repertório ao público.

Pretendo demonstrar que as revistas musicais estrangeiras colecionadas por Mário de Andrade serviram para ampliar os espaços restritos da escuta e constituíram modelos importantes para o crítico de música e ensaísta. Além de escrever para muitos daqueles tipos de publicações, nacionais, no entanto, chegou a editar uma delas, Ariel, por pequeno espaço de tempo.

1. A este respeito veja-se, por exemplo: ANDRADE, 2006; ANDRADE, 1993; ANDRADE, 1976; AZEVEDO, 1956 e AZEVEDO, 1950. 


\section{REVISTAS DE MÚSICA}

O estudo do periodismo no Brasil tem considerado duas datas principais, quais sejam, 1889 - a Proclamação da República - e 1922, a comemoração do centésimo aniversário da Independência do Brasil de Portugal e os Festivais da Semana de Arte Moderna. Esta segunda data funciona como um divisor de águas porque os modernistas comportaramse de forma diferente em relação às revistas após a festividade que os caracterizava como um grupo. Tanto é assim que, naquele mesmo 1922, alguns deles, norteados por Mário de Andrade, organizaram a revista Klaxon, feita em São Paulo, e nos anos seguintes outras revistas foram criadas por alguns membros deste primeiro grupo que às vezes se congregavam em grupos maiores e às vezes introduziam outros colaboradores.

Tão cedo foram escritos os primeiros estudos acerca do Modernismo brasileiro, os historiadores se deram conta da relevância das revistas na divulgação do ideário do movimento, mormente nos campos da literatura e das artes plásticas². Mário de Andrade atuou no periodismo escrevendo sobre música, literatura, cinema, artes plásticas, teatro, artes decorativas, onde conjugava o rigor crítico aos seus exercícios profissionais como professor de música, poeta, ficcionista, cronista, musicólogo, colecionador de arte e de livros raros e fotógrafo.

Para os moços poetas, romancistas, jovens professores nos liceus ou bacharéis, o trabalho nas redações de jornais e revistas era um espaço de trabalho e isto não foi diferente para o caso de Mário de Andrade que, ministrando aulas no Conservatório ou em casa, precisava complementar sua renda. Polígrafo que era, mantinha no jornalismo a possibilidade de veicular suas ideias, através dos ensaios, a criação poética e o exercício téorico. Telê Porto Ancona Lopez realizou exaustivo levantamento junto ao arquivo do escritor e em coleções de periódicos de várias instituições com o intuito de estudar e reunir a produção jornalística dele. Contabilizados jornais e revistas, Mário de Andrade escreveu para 93 deles, do Brasil e do exterior, para alguns apenas um ou dois artigos, e centenas para outros3. O período de 1915 a 1930 pode exemplificar a intensidade do trabalho ao se verificar que, dos 736 artigos para jornais

\footnotetext{
2. Sobre as revistas editadas em São Paulo veja-se, por exemplo: BRITO, 1976; MARTINS, 2006; FERES, 1972 e CHIARELLI, 1996.

3. Dados extraídos do Índice da produção jornalística de Mário de Andrade, Anexo da Livre-docência de Telê Porto Ancona Lopez (Departamento de Letras Clássicas e Vernáculas, Faculdade de Filosofia letras e Ciências Humanas, Universidade de São Paulo, 1991).
} 
e revistas, aproximadamente $45 \%$ versavam sobre música no formato de críticas ou ensaios.

A partir da década de 1960, passou-se a estudar o gesto contrário, ou melhor, não apenas a produção literária, passou-se a estudar o leitor das revistas estrangeiras. Eis a tese de Maria Helena Grembecki sobre $L^{\prime}$ Esprit Nouveau, onde o estudo sobre a influência do ideário e da estética da revista francesa suscita reflexão primordial a respeito dos conceitos de originalidade, imitação e apropriação. $\mathrm{O}$ foco era $\mathrm{o}$ estabelecimento dos elos de ligação entre aquela publicação e a criação do Prefácio Interessantíssimo e da Escrava que não é Isaura.

Embora a tese de Grembecki estude um só dos títulos de revistas assinadas por Mário de Andrade, ela demonstrou que as revistas traziam o que estava em voga na Europa e, no caso da música, pode-se acrescentar que as ideias que elas ajudavam a cultivar eram importantes não só para o professor que preparava as aulas, mas para o crítico que, nas revistas de música, conhecia os repertórios do que se apresentava nas salas e teatros, de concertos de câmara, sinfônico e no mundo da ópera. Nas revistas ele conhecia os novos métodos para o estudo da teoria e dos instrumentos, o que se publicava em musicologia - estudos sobre autores e obras -, as edições de partituras e acompanhava o que eles discutiam entre eles mesmos, como Charles Koechlin a discutir sobre contraponto e fuga ou Georges Migot a discutir sobre estética.

A mesma L'Esprit Nouveau foi importante na formação do jovem professor de música, pois trazia as recentes discussões em torno da Psicologia da Criação, através dos artigos de Théodule Ribot ou Victor Basch, ao mesmo tempo em que o colocava em contato com os últimos versos de Paul Dermée, os traços de Amédée Ozenfant e os espaços arquitetônicos desenhados por Le Corbusier ${ }^{4}$.

As revistas alemãs Deutsche Kunst und Dekoration, Der Sturm, Die Kunst fur Alle, Das Kunstblatt e Die Kunst foram analisadas por Rosângela Asche de Paula (2001) em tese onde buscou as matrizes da criação do aprendiz de fotógrafo que empunhava uma Kodak e as do jovem designer que esboçou os móveis do escritório.

Para acompanhar a produção fílmica, Mário de Andrade também procurava periódicos, como recentemente estudou Paulo José da Silva Cunha (2009) enumerando vinte e seis títulos de periódicos, quatro deles de Música, onde as notas do leitor demonstram o interesse por conhecer técnicas, diretores, roteiros, música e atores. Da França ele lia Bifur,

4. Veja-se, a respeito, CARVALHO, 2009. 
Cahiers d'art, Le Cinéopse, Le Crapouillot, L'Esprit Nouveau, Europe, Les Feuilles Libres, Je Sais Tout, Lumiére, Le Mois, Le Monde Musical, La Revue Musicale, Lecture pour Tous; da Alemanha, Musikblatter des Anbruch, Anbruch, Das Kunstblatt e Der Querschnitt ; da Itália, Cronache d' Attualitá e Rivista Musicale Italiana ; da Inglaterra, The London Mercury e Film e do Brasil, Clima, Papel e Tinta, Para Todos, Revista do Brasil e Revista Presente.

No campo da música, as contribuições para a exploração das revistas que nutriram o conhecimento, a crítica e a criação em Mário de Andrade são recentes. Valquíria Marotti Carozze (2012) trouxe à tona o papel de alguns títulos na dissertação que analisou a parceria entre o professor e a discípula Oneyda Alvarenga. No trajeto que a preparou para a direção da Discoteca Pública fundada no âmago do Departamento de Cultura, Le monde Musical, The Musical Quarterly, Le Menestrel e La Revue Musicale foram divulgadoras de matérias que compartilhavam experiências a respeito da formação do gosto e da divulgação da música, além de noticiarem os lançamentos de discos e livros.

Luciana Barongeno (2012), de outro lado, pinçou ensaio de 1921 publicado na Revista do Brasil onde Mário de Andrade debruçou-se sobre a obra de Claude Debussy, texto que nutriu a conferência proferida na Vila Kyrial, de Freitas Vale, naquele mesmo ano. A autora recorreu aos ensinamentos que o jovem esteta buscara em La Revue Musicale e em Le Monde Musical, palco de onde emanaram os conceitos articuladores das vanguardas europeias.

Embora seja quase um senso comum supor que um jornalista e professor do Conservatório trabalhasse com revistas especializadas no preparo das aulas e na atualização do conhecimento, no estudo sobre a contribuição marioandradiana para a música estes dados são raros. Os primeiros exercícios de conjugação entre a consulta às fontes e a redação de artigos podem ser lidos em duas matérias que ele dedicou a um exprofessor. Aluno do estabelecimento fundado pela família Gomes Cardim, onde já atuava como colaborador nas disciplinas de Estética e História da Música, na coluna intitulada "Música moderna", dedicou os dois textos a Giuseppe Wancolle - com quem estudara piano - assinando-os ainda como "Mário de Morais Andrade".

O primeiro artigo inicia com a surpresa do moço jornalista ao verificar que provavelmente o mundo estava ficando pequeno após o término da guerra:

Devido por ventura às demasias da correspondência universal, ao baralhamento das gentes pelas facilidades das comunicações e das viagens, e mais ainda ao critério de perfeito ecletismo que rege a educação nos nossos 
tempos, propriamente falando, desapareceram da literatura as facções e as escolas (ANDRADE, 1918a).

Ele se reconhecia confuso mediante as rápidas mudanças estéticas da música europeia, pois "Acobertados com a designação de música moderna acham-se os mais dessemelhantes e irregulares credos de arte", exceção honrosa fosse feita ao verismo italiano (ANDRADE, 1918a). A questão era muito preocupante:

As palavras mudam muitas vezes de sentido com o indiferente desenvolver das eras: talvez os nossos bisnetos imaginem que, por estas épocas moderno significava caótico. Evidentemente nunca se aproximaram tanto os dois adjetivos; e não há diferença alguma que os distinga quando pelo adjetivo "moderno" se aquilata do estado atual das literaturas e da música (ANDRADE, 1918a).

Aqueles que chamavam para si mesmos o adjetivo "moderno" eram os seguidores de Richard Wagner, como Vincent D’Indy, Fauré, Debussy, Ravel, Dukas, Rabaud e Massenet, "o último que explanou as delicadezas e o meio-termo que eram as características da Escola Francesa [...]”. Mas Saint-Saens era uma outra história, não podia ser colocado na mesma safra o pai de Sansão, aquele que escrevera "Mon coeur s'ouvre a ta voix", "[...] a mais sublime melodia que explodiu dum coração humano" (ANDRADE, 1918a).

O trecho seguinte, embora longo, importa para se entender porque de Puccini o crítico não queria nem falar, assim como considerava certo abuso filiar os russos ao autor de Tristão, cuja influência avassaladora via dissipar-se:

[...] Poder-se-á mesmo dizer que na Alemanha o seu influxo [de Wagner] foi antes dispersivo e iconoclasta que gerador e bom. Da esperança orgulhosa da escalada, dos céus é que nasceram as babéis e as lendas dos Titãs: modernamente, as duas orgulhosas esperanças de instauração duma música alemã dominadora e duma hegemonia militar germânica sobre todas as gentes e civilizações, ao passo que restaurava as forças adversárias, produzia, aquela, o aniquilamento em que jaz a música alemã, só tendo produzido de grandes Brahms e Strauss, esta, o aniquilamento duma raça que pudera ser grande, mas que está a morrer devorada pelas suas próprias impulsões desvairadas. E assim a música moderna reúne, sob um mesmo pendão, Debussy, Scriabine, Strauss e Gaudonai. Com a mesma bandeira, naturalizam-se numa só pátria artística errares estéticos e temperamentos originais, mediocridades e grandezas. Ensombram-se com a mesma designação as harmonias indecisas e o humorismo de Debussy e as extravagâncias com que o esnobismo de alguns músicos contemporâneos pretendem rivalizar e quiçá obumbrar a serena marcha com que os Gênios escalam os pináculos da glorificação. 
Na sequência, Mário de Andrade continuava avesso ao ecletismo e liberdades de então porque poderiam encobrir a vulgaridade, reiterando sua devoção a Saint-Saens. O compositor tivera a oportunidade de conhecer a partitura de uma recente produção norte-americana, de autor não nomeado, e ficara surpreso com o fato de que a produção do drama lírico mascarava uma composição bem comportada, "bem feita e pouco original” (ANDRADE, 1918b). A conclusão de nosso escritor era direta: "Se há uma verdadeira característica na música moderna será esse desejo de rebuscas esquisitas e de originalidade. Mas são muito mais fáceis de realizar-se como teoria que como prática" (ANDRADE, 1918b).

Invocando a originalidade de Debussy, Mário de Andrade pedia o apoio de Agostino Cameroni, onde lera sobre Pelleas et Melisande, embora um outro crítico, Octave Séré, vaticinasse que o mestre impressionista não faria escola por ter esgotado "[...] nas suas obras os recursos que lhe auferiam os seus processos harmônicos; [...]". Mas tudo não passava, provavelmente, de conversa de revistas de música, ou quase tudo. Curiosamente, ao final do artigo, o jornalista nomeou as "Obras citadas":

Saint-Saens, École huisseniére;

Agostinho Cameroni, Debussy e la musica contemporânea, art [artigo] da Vita e Pensiero, maio de 1918;

Octave Séré, Musiciens Français d'aujourd'hui - citado de segunda mão por não ter sido possível ainda conseguir o livro (ANDRADE, 1918b).

Para os músicos profissionais, associado ao empenho de conhecer a opinião de críticos e musicólogos, havia a necessidade de atualizar o repertório, uma vez que as salas de concerto em geral reprisavam os românticos, música de câmara limitada numericamente a duos ou trios que revezavam no palco com as temporadas de ópera do segundo semestre. As partituras chegavam pelo correio, como a obra de Luis Gianneo, Suite para piano, neste caso acompanhada pela carta de Juan Carlos Paz, secretário do Grupo Renovación e anunciando a recente edição da coleção dirigida por Francisco Curt Lange.

Mas a peça de Ernest Krenek (sem data), autor pouco comum de se encontrar, foi adquirida, provavelmente, pelo interesse que despertava o nome do compositor que assinava muitos dos artigos editados pela Anbruch, revista austríaca patrocinada pela Universal, a mesma editora da partitura. A edição de Reisebuch aus den osterreichischen Alpen, da Universal, não deve ter custado pouco, pois, além de numerada - o exemplar de Mário é o de número 96 - traz quatro gravuras em metal assinadas pela artista Herta Matura. 
Também da Universal provém a obra Barabau, de Vittori Rieti, cuja análise do crítico e professor do Conservatório foi datada:

\begin{abstract}
A Sonatina, os Dois Estudos, Barabau... são pro nosso tempo as manifestações mais brilhantes, mais violentas de juvenilidade. É lindo, é fácil, é franco, duma jovialidade, duma vontade de brincar, porém brincar por brincar, por ser moço e não por estar gasto de tanto sofrimento...E é puro dentro duma breve canalhice...É moço enfim, inteiramente moço./ Como qualidade de musicalidade Vittorio Rietti está pertinho de Mozart...possivelmente alcançará Mozart./ 22-VIII-926.
\end{abstract}

No entanto, foi provavelmente uma revista inglesa que noticiou a edição de obra da jovem escola italiana que tinha em G. Francesco Malipiero compositor de proa. Rispetti e Strambotti, publicada em Londres pela J. e W. Chester (1921), foi analisada com cuidado e este quarteto italiano, escrito em 1920, teve várias notas comentando temas e desenvolvimentos do compositor, sendo os dois últimos comentários representativos do teor da critica de Mário. À página 35, referindo-se ao no 15 :

Estupendo apesar do cosmopolitismo (atrás)". No verso, vem: "Reparar que Malipiero nunca é temático. Não só no sentido de não desenvolver o tema como também porque em geral não cria temas, motivos porém largas frases melódicas. Até pra criar o motivo conjugador das partes deste quarteto se inspirou na afinação das cordas, não criou o tema como Mussorgski nos Quadros da Exposição por exemplo. Nisso vem em grande parte ser Malipiero italiano.

\title{
À MODA DE PAGANEL
}

Através das revistas Mário de Andrade acompanhava o que se falava sobre a música ocidental, de concerto, bem como o que se estudava a respeito da música de povos próximos ou distantes, assunto que também lhe era caro. Às vezes acontecia que pudesse ler até mesmo sobre a música do Brasil ou sobre a que os brasileiros que estavam na Europa compunham ou executavam.

Para facilitar a visão do conjunto dos periódicos de música estrangeiros assinados por Mário de Andrade, realizei uma primeira classificação por países de origem, mesmo sabendo que ela é muito redutora. Associei, na medida do cabível, alguma informação a respeito do número de exemplares ou da periodicidade, análise que não foi feita de forma uniforme porque meu foco de interesse é outro e porque é sabido 
que muitas revistas tiveram vida efêmera a ponto de não se localizar informação alguma a respeito delas. Este talvez seja o caso de um dos dois títulos das revistas da Argentina, a Compas, porque a Revista de Musica, mensal, que circulou entre 1927 e 1930, está praticamente completa na biblioteca do escritor. Outra revista sul-americana que aparentemente teve vida breve mas que está quase completa é a colombiana Musica, publicação da Orquesta Sinfônica Nacional, que circulou entre 1941 e 1942. Ainda da América do Sul, dois títulos importantes para a divulgação da produção musical brasileira e com contribuições do próprio Mário de Andrade, ou seja, o Boletin Lariniamericano de Musica - presente pelos números de 1935, 1936, 1938 e 1941 - e Musica Viva, as duas revistas associadas a Francisco Curt Lange. Na coleção do musicólogo brasileiro, há a presença do número de 1946 do Boletin, com o artigo Danças Dramáticas, de sua autoria, mas que ele não chegou a folhear.

Da Alemanha, tratando de música, há apenas dois títulos de revistas, fracamente representadas em números de exemplares e sobre as quais também pouco se sabe, a Blätter der Staatsoper, de março de 1925, um opúsculo dedicado a Richard Strauss, fartamente ilustrado com propagandas de gravadoras de discos, e a Die Bottscherstrasse Internazionale Zeitschrift, de 1930. Mas da revista patrocinada pela Universal-Edition, a austríaca Musikblätter des Anbruch (1919-1937), Mário de Andrade colecionou a partir de 1926 acompanhando-a até 1935. No campo da música moderna, este foi o principal órgão divulgador da Escola de Viena, porque nele escreviam ou eram editores os alunos e amigos próximos a Arnold Schoenberg e Alban Berg, como Paul Stefan, Theodor Adorno, Bela Bartok, Paul Hindemith, Darius Milhaud, Paul Becker ou Rudolf Réti.

Cito como exemplo o primeiro número da Musikblätter des Anbruch que encontramos hoje no acervo do musicólogo, o fascículo de 1926 (ano 8), e em artigo sobre música de câmara italiana assinado por Max Ettinger onde foram destacados os nomes de Ottorino Respighi e Vittorio Rieti. Na contracapa do exemplar, Mário de Andrade assinalou também a Suíte Opus 25 de Schoenberg e os Quatro Romances Opus 31 de A. Tscherepnin, da mesma forma que, em vários outros fascículos, destacou e fez comprar obras de Bela Bartok, Ernest Krenek, Igor Strawinsky ou Victor Belaiev.

A polonesa Muzyka, Miesiecznik ilustrowany, de 1928, exemplifica o tipo de publicação que hoje está na coleção dele e foi incorporada não como assinatura regular, como exemplar doado por algum amigo. Neste caso, no número 12 do periódico editado em Varsóvia, às páginas 577-580, encontra-se artigo do pianista Artur Rubinstein, intitulado "Villa Lobos", texto que apareceu também na francesa La Revue Musicale, dedicada ao 
compositor brasileiro, número temático de 1928. Poucos também foram os exemplares das portuguesas Arquivo Musical Português, dirigida por César Leiria entre 1939 e 1946, da qual Mário de Andrade tinha os exemplares saídos entre 1941 e 1943, e de Musica, revista dos alunos do Conservatório do Porto, dirigida por Maria Adelaide Diogo Freitas Gonçalves, da qual ele possuía um número de 1942.

Mário de Andrade assinava as revistas francesas Le Menestrel. Musique et theatres; Le Monde Musical; Musique. Revue mensuelle de critique, d'histoire, d'ésthetique et d' information musicales e La Revue Musicale, embora haja alguns exemplares de Le Menestrel dos anos 1900-1902. Embora o meu objetivo não seja elaborar uma análise sobre o periodismo musical europeu, comparei dois números destas revistas levando em conta a importância delas para o professor do Conservatório Dramático e Musical de São Paulo, mesmo que estes periódicos dispensem hoje adjetivos ou teses porque foram bastante bem estudados na musicologia universal.

A 16 de janeiro de 1922, o público da Salle Gaveau pode escutar a estreia francesa de Pierrot Lunaire, melodrama em 21 partes para voz e pequeno conjunto escrito por Arnold Schoenberg. A obra chegava a Paris dez anos depois de escrita em Berlim, em outubro de 1912, mas, na capital francesa, as revistas disputaram espaço para as homenagens. A crítica para a Le Monde Musical foi assinada por Charles Koechlin (1922) e o grande teórico não poupou elogios à execução que já considerava um clássico e datou o artigo no dia 13 de fevereiro de 1922. Aliás, em São Paulo, talvez ainda colhendo os frutos e as críticas da Semana de Arte Moderna, Mário de Andrade também pode acompanhar pela mesma revista francesa a turnê da cantora brasileira Vera Janacopulos pelas salas da Espanha e de Portugal através de várias críticas transcritas nos exemplares de maio de 1922 (VERA JANACOPULOS, 1922, p. 197).

De La Revue Musicale tomei o número 5, datado de $1^{\circ}$ de março de 1922: era uma revista com grande quantidade de anunciantes de música, ainda que trouxesse matérias densas sobre teoria e biografias de autores, uma revista com porte de livro, pela classificação de Luiz Heitor Corrêa de Azevedo. O musicólogo carioca, que se inspirara na Revue para a reestruturação da Revista da Associação Brasileira de Música, por ele fundada e, a partir de 1934, batizada de Revista Brasileira de Música, entendia que este tipo de publicação se caracterizava como "[....] de alta cultura, sem estampas, sem concessões ao público, austera como um livro de estudos" (AZEVEDO, 1950, p. 78). Havia certamente muita variedade entre elas, na distribuição da matéria, quanto às correntes 
estéticas que defendiam, de que forma administravam os espaços pagos pelos patrocinadores, entre muitos outros aspectos.

O espaço para as críticas de concertos de La Revue Musicale, seção batizada de "Chroniques et Notes", era disputado pelos melhores repertório e autores. Um deles, Egon Wellesz, correspondente austríaco que posteriormente viria a ser celebrado como bom compositor, escreveu orgulhoso ao narrar uma das audições de música que tivera a satisfação de conferir. Era um homem de sorte porque acompanhara o desfecho feliz do "ciúme" de Arnold Schoenberg ao saber que Pierrot Lunaire fora apresentado em Paris no idioma original:

Quelques jours plus tard eu lieu une séance musicale fort intéressante chez Mme Alma Mahler. Schoenberg, qui avait entendu parler de l'éxecution de son Pierrot Lunaire à Paris, voulait l' entendre dans l' interprétation Française. De son coté Milhaud était désireux de connaître l'interprétation de Schoenberg: on décida de donner Pierrot d'abord avec Erika Wagner et le chef d'orchestre Erwin Stein selon la tradition schoenbergienne, puis avec Marya Freund sous la direction de Milhaud (WELLESZ, 1922, p. 271).

Prudente, entendeu que seria melhor aprovar ambas as versões: “[...] j' ai trouvé l' une et l' autre absolument réussie dans son genre" (WELLESZ, 1922, p. 271).

Para contrapor a Revue ao Le Monde Musical, tomei os números 1 e 2, de janeiro de 1922 (ano 33, Paris) desta última. O simples folhear aponta algumas das diferenças, como o fato de que ela é muito mais ilustrada, com propagandas e fotos, há notícias sobre os concertos, as matérias são curtas, ela era mais próxima de uma revista de variedades. De qualquer forma, no índice das matérias estampadas em 1921, figuravam entre os autores os nomes de Jacques Dalcroze, Claude Debussy, Theodore Dubois, Charles Koechlin, A. Mangeot, Georges Migot, Isidor Philipp, Romain Rolland ou Saint-Saens.

Acompanhando os números da revista mensal durante o ano, foi possível observar que, muito vinculada à temporada dos concertos, quando noticiava os programas das grandes salas da cidade de Paris e de capitais europeias, pouco antes da metade do ano, dedicavase ao noticiário sobre os exames das escolas de música e, no verão, às atividades dos compositores. Mas duas prováveis coincidências não deixam de apontar para a dinâmica das notícias musicais que comoviam o musicólogo que acompanhava o noticiário de sua poltrona na Rua Lopes Chaves.

Convém destacar que a presença física das revistas de música nas prateleiras da biblioteca de Mário de Andrade não significa que ele as 
conhecesse apenas pelos títulos que ali estão representados porque muitos deles ele podia ler no Conservatório Dramático e Musical. Mas, das quatro principais revistas italianas que recebia em sua casa, a Rivista Musicale Italiana cobre o maior período contínuo na biblioteca dele, ao lado de La Revue Musicale e Le Monde Musical, ou seja, entre 1920 e 1940. Publicada pela Fratelli Bocca Editori, de Torino, importante casa impressora de partituras, sobretudo de óperas, a Rivista era estruturada de forma bastante homogênea, trazendo uma parte dedicada a artigos sobre história da música e teoria e uma outra para assuntos da atualidade. Tomei para análise o volume 29, de 1922, e naquele exemplar escreveram Gaetano Cesari, A. Pougin e Paolo Guerrini, na parte chamada de "Memorie", e Gaetano Cesari, J.-G. Prod' Homme e Jean Marnold, na parte chamada de "Arte Contemporanea". Completando o número, resenhas sobre livros, cartas e críticas de concertos onde o leitor destacou trecho da crítica para o livro L'évolution théatrale quando o autor, Lucien Solvay, mencionou Meyerbeer, Halevy e Massenet. Os traços do lápis vermelho anunciam o que se comprova nas estantes do Instituto de Estudos Brasileiros, ou seja, Mário de Andrade não se satisfez com a resenha do autor anônimo e comprou este livro de Solvay.

No número seguinte da Rivista, do mesmo 1922, se por um lado se comprova o que foi observado acima, a respeito das principais partes da publicação, há um aspecto novo entre os temas abordados por estes periódicos europeus que estão em tela, ou seja, um artigo sobre música folclórica. Em "Memorie", Giulio Fara escreveu ensaio dedicado à música da Sardenha com análises de melodias, descrições de instrumentos e mapas da região. No início do texto, bem humorado, o musicólogo italiano comparou-se a Jacques Paganel, o personagem de Les enfants du capitaine Grant, de Jules Verne, confessando já ter colecionado muitos dados sobre música, mas que, sentado em sua poltrona, chegara a hora de publicá-los.

As demais revistas italianas repetem a prática das editoras de partituras, sobretudo aquelas que editavam para o piano, de manterem seus próprios periódicos para a divulgação de lançamentos, como a Pianoforte (1920/1927) - Mário de Andrade possuía os exemplares publicados entre 1921 e 1923; a Vita musicale italiana, de Nápoles, chamada de Arte pianistica editrice, que ele manteve entre 1926 e 1927; e Musica d' oggi, editado em Milão, pela Riccordi (1919-1965), da qual ele guardou ou recebeu os números de 1927 a 1931 e de 1936 teve um dos números.

Das revistas inglesas as proeminentes foram Music $\mathcal{E}$ Letters, entre 1933 e 1936, e Fanfare, importante destaque, pois, apesar da vida efêmera, foi provavelmente a matriz para a brasileira Ariel, que o próprio Mário de 
Andrade dirigiu em 1924. Editada por Leigh Henry, Fanfare circulou entre outubro de 1921 e janeiro de 1922, pretendendo ser quinzenal. Mesmo trazendo propagandas de editoras de música como Winthrop Rogers ou Harold Reeves, ou de revistas, como The Sackbut, e de sociedades de concertos, não possuía uma patrocinadora. A periodicidade e as imagens que provavelmente encareciam-na decretaram sua falência. Henry, compositor e crítico de música que vivera na Itália, era bem relacionado no campo da música e conseguiu levar os nomes de jovens expoentes para as páginas da revista que para ela assinavam trechos de alguns compassos de fanfarras. Ali foram editadas pequenas obras de Manuel de Falla, E. Satie, F. Poulenc, S. Prokofiev, Darius Milhaud, Egon Wellesz, Francisco Malipiero, mas, como estas obras somaram vinte e quatro ao longo dos sete fascículos de duração do periódico, mencionei apenas os autores mais conhecidos.

Ao longo dos sete números de existência, Fanfare mostrou-se um tanto dispersiva no sentido de que publicou algum poema, alguma crítica, alguma matéria teórica, mas sem continuidade, exceção feita aos trechos para fanfarra, que foram apresentados sempre em número de quatro em cada um dos primeiros seis números, ou aos editoriais, sempre assinados por Leigh Henry. Mário de Andrade chegou mesmo a destacar o trecho de um deles, "Men-in-the-street":

Group-forces are probably more massive today than ever before, the result of disconcertingly rapid evolutions of physical and social conditions. But, more than ever before, these evolutions trace directly to individual contributions to research and invention, and the results in turn evoke from the old, herdlike mass emotionalism a new consciousness of its components members. And with this the old symbol of stereotyped opinion, the man-inthe-street, gradually disintegrates. For the spiritual development of mankind moves with the physical one of the universe: physical factors produce new states of existence; new states of existence create new thought; new thought in turn creates new systems of ideas, new types of activity. Man-in-the-street is a term without significance except in a spiritual sense.

E, adiante, o início apenas de uma frase: "We are all men-in-thestreet, artists or artisans".

Henry planejava uma reviravolta na vida de sua revista e chegou a anunciá-la ao leitor com a expectativa de sobrevivência da publicação, mas o número 7, o derradeiro, ao invés de um manuscrito para conjunto de metais, estampou quatro páginas da partitura de Petrouchka, do amigo Strawinsky.

Fanfare se destaca nas prateleiras da biblioteca de Mário de Andrade não apenas pela beleza da edição, que apresenta principalmente 
propagandas de outras revistas. Curiosamente os sete números dela foram encadernados caprichosamente com capa dura revestida de linho, lombada dourada e folhas brancas no final.

Também na língua inglesa, mas editadas nos Estados Unidos, nas prateleiras da casa de Mário de Andrade, havia espaço para abrigar publicações tão célebres quanto a Music Educators Journal, iniciada em 1914 e representada na coleção dele nos anos de 1941 a 1944, e The Musical Quarterly, presente nos períodos 1920/1921; 1931/1932 e 1936/1940.

Complementando o quadro das revistas europeias que Mário de Andrade recebeu em casa, há duas publicações espanholas, ambas de 1929, cada uma com um exemplar apenas: Musica. Ilustración IberoAmericana e Tesouro Sacro-Musical.

\section{O “ESPÓLIO” DOS PERIÓDICOS}

Os periódicos, exclusivamente musicais ou não, geralmente dedicavam uma coluna para a divulgação de revistas de outras editoras e de procedências as mais variadas. A prática podia ser curiosa quando eles se restringiam a elencar títulos agrupados por países de origem, sem resenhas ou descrição de conteúdos. No primeiro número da brasileira Ariel, de outubro de 1923, na seção "Revista da Revistas", foram elencados os títulos de periódicos europeus e norte-americanos publicados entre os meses de maio e agosto daquele ano. Da França os editores mencionaram La Revue Musicale, Le Monde Musical, Le courier Musical, Intentions e Le Menestrel; da Inglaterra, The Chesterian e The Sackbut; da Alemanha e da Áustria foram selecionadas Die Musik. Allgemeine Musikzeitung; Signale fur die Musikalische Welt, Anbruch; da Tchecoslováquia, Der Auftakt; dos Estados Unidos, The Musical Quarterly, Musical Courier, Musical America e The Etude e da Itália, Il Pianoforte, Rivista Musicale Italiana, L' Arte Pianistica e Musica d' Oggi.

Para se ter uma ideia da forma como estes periódicos circulavam pelas redações e o quão importante era o apoio das revistas entre elas, compare-se o espaço de Ariel com os títulos que a Rivista musicale italiana destacou em 1922, no volume 29 mencionado acima, coluna "Spoglio dei periodici”. Para facilitar a leitura, desloquei propositalmente a disposição original da revista.

Da França não há menção a nenhum periódico; da Inglaterra foram citados Monthly Musical Record, The Chesterian, The Musical Times e The Sackbut; da Alemanha e Áustria, Allgemeine Musik-Zeitung, Musikblatter des Anbruch, Signale fur di Musikalische Welt, Zeitschrift 
fur Musik e Zeitschrfit fur Musikwissenschaft; da Tchecoslováquia não há menção alguma; dos Estados Unidos foram contempladas The Etude e The Musical Quarterly e da Itália, Cronache d'attualittá, Il Pianoforte, La critica musicale, L'arte pianistica, Musica d' oggi e Musica italiana.

Olhando-se a seção "Revista das Revistas", de Ariel, surpreende a variedade dos títulos mencionados e o número de publicações contempladas que provavelmente tinham assinaturas que resultavam caras, tendo em vista o valor que se pagava ao correio e demais despesas de transporte. Pode-se supor que nem todas elas pertencessem ao editor daquele período da vida do seriado, Antonio de Sá Pereira. Algumas talvez fossem assinadas pelo Conservatório Dramático e Musical, onde ele lecionava, outras eram provavelmente das prateleiras de Mário de Andrade. Em tempos de paz, as revistas chegavam rapidamente às redações das outras revistas e aos assinantes comuns, e entre as que chegavam à rua Lopes Chaves, em São Paulo, muitas embarcavam novamente para o Rio de Janeiro. A troca de cartas entre o musicólogo e Manuel Bandeira possui duas menções a propósito, nos idos da Revolução Paulista de 1924, quando o poeta pernambucano instava Mário de Andrade a redigir uma História da Música Brasileira e, ele próprio, consultava o compositor Vincent d'Indy a respeito do repertório para o violão.

Bandeira entusiasmara-se com a possibilidade de escrever a respeito do instrumento de cordas ao qual se dedicava com certa tenacidade e chegou a enviar algumas ilustrações para a revista Guitarre, de Pablo Picasso. Entre as idas e vindas de cartas, ele mencionou o empréstimo de dois exemplares de La Revue Musicale, nomeando, a 30 de setembro de 1924, o número de julho (ANDRADE, 2000, p. 128). É tentador imaginar de qual dos artigos ele teria gostado mais entre aqueles que recheiam o número 9 da revista, assinados por musicólogos, críticos e filósofos que o tempo consagraria com a devida nuance: "Un mélodrame du XVIII siécle", de Yves Lacroix (p. 1-12); "La 'Matthaeus Passion' commentée par un saint homme”, de Marc Pincherle (p. 13-18); "Michel Ange et la Musique”, por Marie Dormoy (p. 19-25); “Un jongleur du XX Siécle”, por Leon Kochnitzky (p. 26-28); "Richard Wagner en contact avec l'esprit français”, por Robert Jardillier (p. 29-50) ou "La Musique et les ressemblances générales", por Lionel Dauriac (p. 51-58)?

\section{“UMA PORRADA DE MÚSICAS”}

A análise do conjunto de revistas de música colecionadas por Mário de Andrade pode apresentar alguns pontos de interesse, como 
a concentração do maior número de assinaturas no período de 1927 a 1930, verificação válida tanto para as revistas brasileiras quanto para as estrangeiras. Mas as estatísticas escondem, por exemplo, que a revista francesa Monde Musical o acompanhou durante toda a vida profissional, pois ele tem os números que preenchem o período de 1920 a 1940.

As orientações estéticas destes periódicos são bastante heterogêneas. De um lado, há periódicos aparentemente moderados, como o mencionado Monde Musical, cujos primeiros números da coleção, datados de 1920, trazem artigos assinados por Nadia Boulanger, Charles Koechlin ou J. R. Thieffry.

A análise do conjunto de títulos, por sua vez, reforça um aspecto pouco destacado, porque, na segunda metade da década de 1920, a produção periodística de Mário de Andrade foi mesmo muito grande. Mas faz-se necessário salientar uma última questão em relação a esta análise: foram relacionadas apenas as revistas de música e, se somarmos as de campos de conhecimento específicos, como literatura ou artes plásticas, além daquelas aqui mencionadas anteriormente, alcançamos a casa das centenas de títulos e, muito provavelmente, um resultado diverso.

No entanto, as expressões mais significativas sobre a importância das revistas estrangeiras no pensamento de Mário de Andrade ou no círculo que estreita as amizades e colaboração dos intelectuais modernistas devem ser buscadas nos escritos dele, artigos, crônicas e correspondência.

A título de exemplo, menciono novamente Ariel: revista de Cultura Musical. Fundada em outubro de 1923, com sede na cidade de São Paulo, teve o pianista Antonio de Sá Pereira como Diretor e Mário de Andrade numa fase seguinte, entre junho e outubro de 1924. A quase ausência de propagandas, o tom um tanto panfletário dos primeiros números e a preocupação com a ilustração de qualidade aproximam-na, pelo menos aparentemente, à inglesa Fanfare.

A revista, embora voltada à música, contava com colaboradores de vários campos do saber, como Sérgio Milliet, Álvaro Moreyra, Renato Almeida, Yan de Almeida Prado, Furio Franceschini, Mário de Andrade e Manuel Bandeira. Eram eles que se encarregavam também de encomendar artigos para autores estrangeiros, como Jacques Dalcoze ou Darius Milhaud.

Entre junho e outubro de 1924, Mário de Andrade dirigiu Ariel, fase durante a qual a revista contou com a subvenção da editora Campassi \& Camin. No início bastante animado, ele chegou a simular o papel de um correspondente que contaria as novidades do mundo da música e contou 
os planos de mudança nos padrões da revista para o amigo Sérgio Milliet, um dos colaboradores:

Olha estou escrevendo umas cartas de Paris para Ariel que assinei com um nome francês imaginário. E o sujeito diz que conhece o Souza Lima, VillaLobos, tu. Avise os outros, por favor, para que não se assustem. Aliás é brincadeira que não faz mal. Não poderias arranjar com o Souza Lima para que escreva qualquer coisa para Ariel? Sem pagar, naturalmente. O estado financeiro da revista é miserável. "Déficit": onze contos.

Tomei a direção da revista, porque o Sá Pereira não tinha coragem para piorála, torná-la acessível a este público bunda do Brasil. Pois eu pioro? disse. Fiz revista informativa, mais variada, sem artigos pesados, cheia de notícias idiotas e elogio todo mundo. [...] Vamos ver se a diaba vive (DUARTE, 1985, p. 298) (Carta de 11 de agosto de 1924).

Concluindo, acredito ter ficado evidente que as revistas musicais estrangeiras tiveram papel significativo não apenas no fortalecimento das redes de sociabilidade alimentadas pelos intelectuais que nelas trabalharam, como também colaboraram na afirmação dos postulados do modernismo brasileiro, o que caberá ainda aprofundar no tocante à musicologia. Não há dúvida, porém, de que elas auxiliaram na atualização do conhecimento e na ampliação do repertório do musicólogo Mário de Andrade. A 18 de novembro de 1924, poucas semanas após o fechamento de Ariel, não pode ter sido coincidência o fato de ele contar entusiasmado para Sérgio Milliet: “Acabo de receber uma porrada de músicas de Stravinski, Falla, Honegger, Milhaud, Satie. Estou contente” (DUARTE, 1985, p. 296).

\section{REFERÊNCIAS BIBLIOGRÁFICAS}

ANCONA LOPEZ, Telê. Produção jornalística de Mário de Andrade. Tese de livredocência. São Paulo, Faculdade de Filosofia Letras e Ciências Humanas, 1991.

ANDRADE, Mário de. Correspondência. Estabelecimento de texto, introdução e notas de Marcos Antonio de Moraes. São Paulo: Edusp, 2000.

. Música, Doce Música. $3^{\mathrm{a}}$ Ed. Belo Horizonte: Itatiaia, 2006.

- Música e Jornalismo: Diário de S Paulo. Pesquisa, estabelecimento do texto, introdução e notas de Paulo Castagna. São Paulo: Edusp; Hucitec, 1993.

. Taxi e Crônicas no Diário Nacional. Estabelecimento de Texto, Introdução e Notas de Telê Porto Ancona Lopez. São Paulo: Duas Cidades; SCCET, 1976

ANDRADE, Mário de Morais. Para Giuseppe Wancolle I. Gazeta, São Paulo, 31 jun. 1918a. Série matérias extraídas de periódicos; Arquivo Mário de Andrade, Instituto de Estudos Brasileiros, Universidade de São Paulo. 
. Para Giuseppe Wancolle II. Gazeta, São Paulo, 7 ago. 1918b. Série matérias extraídas de periódicos; Arquivo Mário de Andrade, Instituto de Estudos Brasileiros, Universidade de São Paulo.

ANÔNIMO. Vera Janacopulos. Le Monde Musical. Paris, números 9 e 10, 1922, p.197.

AZEVEDO, Luiz Heitor Correa de. 150 anos de música no Brasil (180o-1950). Rio de Janeiro: Liv. José Olympio, Ed. 1956.

. Periódicos musicais do Brasil. In: Música e músicos do Brasil. Rio de Janeiro: Casa do Estudante, 1950. p. 76-8o. [Artigo de maio de 1946.]

BARONGENO, Luciana. Musicologia e modernismo na biblioteca de Mário de Andrade. I Jornada Acadêmica Discente - PPGMUS/USP, 2012. Anais. In: http://www.pos.eca. usp.br/index.php?q=pt-br/ppgmus/jornada_discente/2012/5379/paper

BRITO, Mário da Silva. O Alegre combate de Klaxon, In: Klaxon: mensário de arte moderna. São Paulo: SCCET, 1976 (edição fac-similar).

CAROZZE, Valquíria Marotti. A menina boba e a discoteca. São Paulo, Instituto de Estudos Brasileiros, Universidade de São Paulo, 2012. Dissertação de Mestrado.

CARVALHO, Lilian Escorel de. A revista francesa L'Esprit Nouveau na formação das idéias estéticas e da poética de Mário de Andrade. São Paulo, Tese de Doutorado. Faculdade de Filosofia, Letras e Ciências Humanas, Universidade de São Paulo, 2009.

CASTAGNA, Paulo. Periódicos musicais brasileiros no contexto das bibliografias e bases de dados na área de música. VII Encontro de musicologia histórica. Juiz de Fora: Centro Cultural Pró-Música, 21-23 de julho de 2006, Anais. Juiz de Fora: Centro Cultural Pró-Música, 2008. p. 21-54.

CHIARELLI, Tadeu. Almeida Jr a Almeida Jr: a crítica de Mário de Andrade. Doutorado, 1996.

CUNHA, Paulo José da Silva. No écran das folhas brancas: o cinema nas leituras, produção jornalística e criação literária de Mário de Andrade. São Paulo, Dissertação de Mestrado. Faculdade de Filosofia, Letras e Ciências Humanas, Universidade de de São Paulo, 2009, p. 20-21.

DUARTE, Paulo. Mário de Andrade por ele mesmo. São Paulo: Hucitec; Secretaria Municipal de Cultura, 1985.

FARA, Giulio. Appunti di etnofonia comparata. Rivista Musicale Italiana. Torino, p. 277334, 1922.

FERES, Nites Therezinha. Aurora de arte século XX: a modernidade e seus veículos de comunicação, 1972.

GIANNEO, Luis. Suíte. Buenos Aires: M. Galvello; Grupo Renovación, 1933. 
244 - Remate de Males 33.1-2

GREMBECKI, Maria Helena. Mário de Andrade e L'Esprit Nouveau. S Paulo: Instituto de Estudos Brasileiros, 1969.

HENRY, Leigh. Men-in-the-street. Fanfare, Londres, n. 6, p. 101/102, 15 dez. 1921.

KOECHLIN, Charles. Pierrot Lunaire. Le Monde Musical. Paris, n. 3 e 4, p. 47-49, 1922.

MARTINS, Ana Luiza. Revistas em Revista. São Paulo: Edusp, 2006.

PAULA, Rosangela Asche de. Mário de Andrade "designer" aprendiz. DO Leitura, São Paulo, a. 19, n. 3, p. 14-21, mar. 2001.

SCHUMANN, Robert. 24 melodie scelte para canto e piano. Milão, Ricordi, s.d. Tradução de Giulio Ricordi e Tito Velli.

SOLVAY, Lucien. L'évolution théatrale. Bruxelas: Ed. G. Von Ouest et Cie., 1922.

VERA JANACOPULOS. Le Monde Musical. Paris, n. 3 e 4, p. 197, 1922.

WELLESZ, Egon. Deux Pierrots Lunaires à Vienne. La Revue Musicale, ano 5, p. 271-272, 1 mar. 1922. 